\title{
Impact of recent guideline changes on aspirin prescribing after knee arthroplasty \\ (a) CrossMark
}

Sarav S. Shah ${ }^{1}$, Alexander M. Satin ${ }^{*}$, James R. Mullen ${ }^{1}$, Sara Merwin ${ }^{2}$, Mark Goldin ${ }^{3}$ and Nicholas A. Sgaglione ${ }^{1}$

\begin{abstract}
Background: Prior to 2012, the American Academy of Orthopaedic Surgeons (AAOS) and American College of Chest Physicians (ACCP) differed in their recommendations for postoperative pharmacologic venous thromboembolism prophylaxis (VTEP) after total joint arthroplasty. More specifically, aspirin (ASA) monotherapy was not endorsed by the ACCP as an acceptable prophylaxis. In 2012, the ACCP supported ASA monotherapy compared with no prophylaxis. Our aim was to investigate the impact of the convergence of ACCP and AAOS recommendations on surgeon prescribing patterns after knee arthroplasty (KA).

Methods: This is a retrospective chart review. We collected data to assess preoperative VTE risk and examined VTEP prescriptions on postoperative day 1 (POD1) and at discharge (D/C) from 7/2008 to 12/2011 (pre-period) and 1/2012 to 7/2014 (post-period). Adult patients undergoing primary and revision KA were identified by ICD-9 procedure codes. Patients on preoperative full-dose anticoagulation and with hypercoagulability disorders were excluded.

Results: Of 368 records reviewed, 329 were included in the analysis. There were no differences between the two period groups for age, sex, BMI, estrogen therapy, malignancy, smoking status, prior VTE, bilateral procedures, or surgery within 3 months. On POD1, in the pre-period, $4.6 \%$ were prescribed ASA monotherapy versus $44.4 \%$ in the post-period $(p<0.001)$. On $\mathrm{D} / \mathrm{C}$, in the pre-period, $13.9 \%$ were prescribed ASA versus $55.6 \%$ in the post-period $(p<0.001)$.

Conclusions: Our results indicate a statistically significant change in orthopedist prescribing patterns after guideline convergence. Furthermore, there was no apparent change in VTE risk between the two study groups when excluding patients necessitating full anticoagulation. Prior literature has shown that the divergence in guidelines influenced physicians away from ASA and toward more potent anticoagulants in order to avoid potential litigation. Once its role in VTEP was supported by the ACCP, it appears that ASA monotherapy was readily and rapidly incorporated into clinical practice. ASA may be favored over other VTEP agents for its lower bleeding risk profile and cost. This study highlights the profound impact clinical practice guidelines have on clinician prescribing patterns. Although prospective randomized trials are needed to compare the efficacy of ASA with other VTEP agents, ASA is now a predominant part of the VTEP armamentarium after KA.
\end{abstract}

\section{Background}

Major orthopedic procedures confer increased risk of venous thromboembolic events (VTE), with rates reported as high as $60 \%$ in the absence of chemoprophylaxis [1]. The use of chemoprophylactic agents has decreased the incidence of VTE following orthopedic procedures to $1-2 \%[2,3]$. Despite significant improvement in outcomes, concern remains over VTE-related

\footnotetext{
* Correspondence: asatin@northwell.edu

'Department of Orthopaedic Surgery, Long Island Jewish Medical Center, 270-05 76th Ave, New Hyde Park, NY 11040, USA

Full list of author information is available at the end of the article
}

complications such as post-thrombotic syndrome, hemodynamic compromise from pulmonary embolism (PE), and death. Furthermore, VTE treatment itself presents risks including heparin-induced thrombocytopenia and major bleeding [4]. As rates of orthopedic procedures increase across the USA [5], the concern for VTE and its related complications grow. Between 1991 and 2010, annual primary total knee arthroplasty (TKA) volume increased $161.5 \%$ from 93,230 to 243,802 [6]. The importance of venous thromboembolism prophylaxis (VTEP) becomes even more apparent when considering the financial burdens associated with VTE. Cost estimates 
range from $\$ 3000$ to 9500 for the initial VTE, and those costs rise significantly when treating the sequelae [7].

Despite the importance of appropriate VTEP, until recently, medical and surgical professional societies presented divergent recommendations on choice of chemoprophylactic agent following joint replacement surgery. There remains limited evidence demonstrating efficacy and superiority of VTEP agents in extended use [8]. Additionally, the risk-benefit analysis balancing prevention of VTE with risk of major bleeding continues to contribute to a lack of consensus on VTEP regimens [8-10]. In 2009 and again in 2011, the American Academy of Orthopaedic Surgeons (AAOS) issued clinical practice guidelines (CPG) using a methodological approach with grades assessing the strength and evidence for patients undergoing hip or knee arthroplasty (KA). Their 2009 recommendations, for the first time, included aspirin (ASA) monotherapy as VTEP $[11,12]$. Recommendations included ASA monotherapy as a chemoprophylactic agent at a dose of $325 \mathrm{mg}$ twice-daily (BID) beginning on the day of surgery and continued for 6 weeks for patients without preoperative elevated VTE risk. Although the AAOS does not specify other VTE factors beyond previous VTE, the workgroup advised individualized assessment for patients deemed to be at elevated risk [13].

The 2011 AAOS recommendations gained support from the 2012 American College of Chest Physicians (ACCP) VTEP guidelines, which for the first time, included daily full-dose ASA ( $>300 \mathrm{mg}$ ) as acceptable chemoprophylactic monotherapy after total joint arthroplasty. The ACCP advised using ASA, low molecular weight heparin (LMWH), fondaparinux, apixaban, dabigatran, rivaroxaban, low-dose unfractionated heparin (LDUH), adjusted-dose vitamin $\mathrm{K}$ antagonist (VKA) (grade 1B recommendations; strong recommendation, moderate-quality evidence) for a minimum of 10-14 days following joint replacement surgery, with LMWH as the preferred agent (grade $2 \mathrm{~B}$ recommendation; weak recommendation, moderate-quality evidence) $[14,15]$.

Evidence-based CPG are compiled to positively influence physicians' practice [16-19]. CPG, including professional society guideline recommendations, have been shown to exert a powerful influence on providers and improve the quality of care administered to patients [16-23]. This investigation's primary purpose is to determine whether the convergence of AAOS and ACCP CPG endorsing the inclusion of ASA monotherapy resulted in a significant change in orthopedic surgeon prescribing patterns.

\section{Methods}

This is a retrospective IRB-approved collaborative cohort study between the Department of Orthopaedic Surgery and the Department of Internal Medicine. The study population consists of patients who underwent KA procedures at two tertiary care academic centers. We identified the patient sample using ICD-9 procedure codes $(81.54,00.80,00.81,00.82,00.83$, and 00.84) which were cross-referenced with ICD-9 diagnosis codes (715.16, 715.36, 996.49, 996.44, 715.96, 716.16, 715.35, 996.66, 714.4, 714.0, 714.9, 716.96, 736.5, and 996.77) to improve validity. The study period spanned July 1, 2008-July 31, 2014 with comparison periods of July 1, 2008-December 31, 2011 (pre-period) and January 1, 2012-July 31, 2014 (post-period). The data pool included every KA procedure performed by a total of 18 surgeons over a 7 -year period. All data was obtained through the electronic health record (EHR). Included subjects were adults having a primary or revision KA. In an effort to control for patients that would necessitate more potent anticoagulation, we excluded patients who received preoperative full-dose anticoagulation and those with hypercoagulability. A biostatistician devised a systematic sampling algorithm to obtain a consistent number of patients for each year investigated and reduce bias that may arise due to single surgeon prescribing patterns. All chart reviewers underwent interreliability assessment to standardize the manner in which data was collected and cycled through the study years to eliminate the potential for systematic error. The study team constructed a comprehensive data dictionary to derive consensus on the variables examined.

Demographic data (age, gender, ethnicity, and insurance status) and validated VTE risk factors (medical comorbidities, body mass index (BMI), personal history of VTE, estrogen therapy, history of malignancy, other surgery within three months, current tobacco use, and unilateral versus bilateral procedures) were collected in addition to the exclusion criteria $[3,24,25]$. We compiled data on all prescribed VTEP agents, including ASA 325 BID, warfarin sodium, LMWH, LDUH, apixaban, rivaraxiban, and fondaparinux, which were then aggregated into classes: ASA monotherapy, VKA, LWMH, Xa inhibitors, LDUH, and combination therapy. ASA monotherapy included ASA 325 BID or ASA 325 BID + clopidogrel; LMWH class included enoxaparin 30 or $40 \mathrm{mg} /$ day, or $30 \mathrm{mg}$ BID; VKA class included warfarin; Xa inhibitor class included fondaparinux, rivaroxaban or apixaban. Combination prophylaxis was defined as any combination of these agents. Time periods were chosen to reflect the introduction of ASA in the ACCP CPG. To assess changes in prescriptions during the hospital stay, we measured VTEP prescriptions on postoperative day 1 (POD1) and at time of discharge $(D / C)$. The primary endpoint was the difference in rates of ASA monotherapy between the pre-period and post-period. Secondary endpoints were differences in chemoprophylactic agents prescribed on POD1 and at D/C, as well as associations between our adjusted VTE risk profiles and choice of agent. 
The chi-square test was used to compare the rates of ASA VTEP between pre-period and post-period. Confidence intervals for the difference in rates were computed. In addition, exploratory graphical analysis was used to describe trajectories of ASA VTEP use over time. Smoothing techniques were used to determine whether trajectories obeyed a particular parametric pattern or patterns that could be modeled using multiple logistic regression as a function of time. Standard multiple logistic regression was used to estimate the probability of ASA VTEP in a specific patient as a function of the predictors listed above, as well as "era" (pre-2012, post-2012). The rates of VTEP change were compared across the two periods using the chi-square test for $2 \times 4$ tables. For patients who were not on ASA monotherapy, a descriptive list of prophylactic agents was produced.

\section{Results}

Of 368 records reviewed, 329 were included in the analysis. For the pre-period, there were 180 cases, 11 meeting exclusion criteria, and 18 with data unobtainable through EHR, resulting in 151 cases. For the post- period, there were 188 cases, 9 meeting exclusion criteria, and 1 with data unobtainable through EHR for a total of 178 cases (Fig. 1); 19 of the 368 charts (5.2 \%) were irretrievable. In the pre-period, there were 55 male patients $(36.4 \%)$ with a mean age of $67.0( \pm 10.7)$ years. In the post-period, there were 67 male patients $(37.6 \%)$ with a mean age of $67.3( \pm 10.4)$ among all patients. The majority of patients in both the pre- and post-periods were obese $(\mathrm{BMI}>30)$ (Table 1$)$.

In the pre-period, 7/151 (4.6\%) subjects received ASA monotherapy on POD1 and 21/151 (13.9 \%) received ASA monotherapy on D/C. In the post-period, 79/178 subjects $(42.1 \%)$ received ASA monotherapy on POD1 and $99 / 178$ (57.8 \%) received ASA monotherapy on D/ C. For both POD1 and D/C, ASA monotherapy rates increased significantly from pre- to post-period $(p<$ 0.0001) (Table 2). In the pre- and post-periods, a majority of subjects had 0-2 adjusted VTE risk factors (72.37 and $69.10 \%$, respectively). The proportion of subjects with three or more risk factors was also comparable between the pre- and post-periods ( 7.24 and $8.99 \%$, respectively). Overall, there was no statistically significant

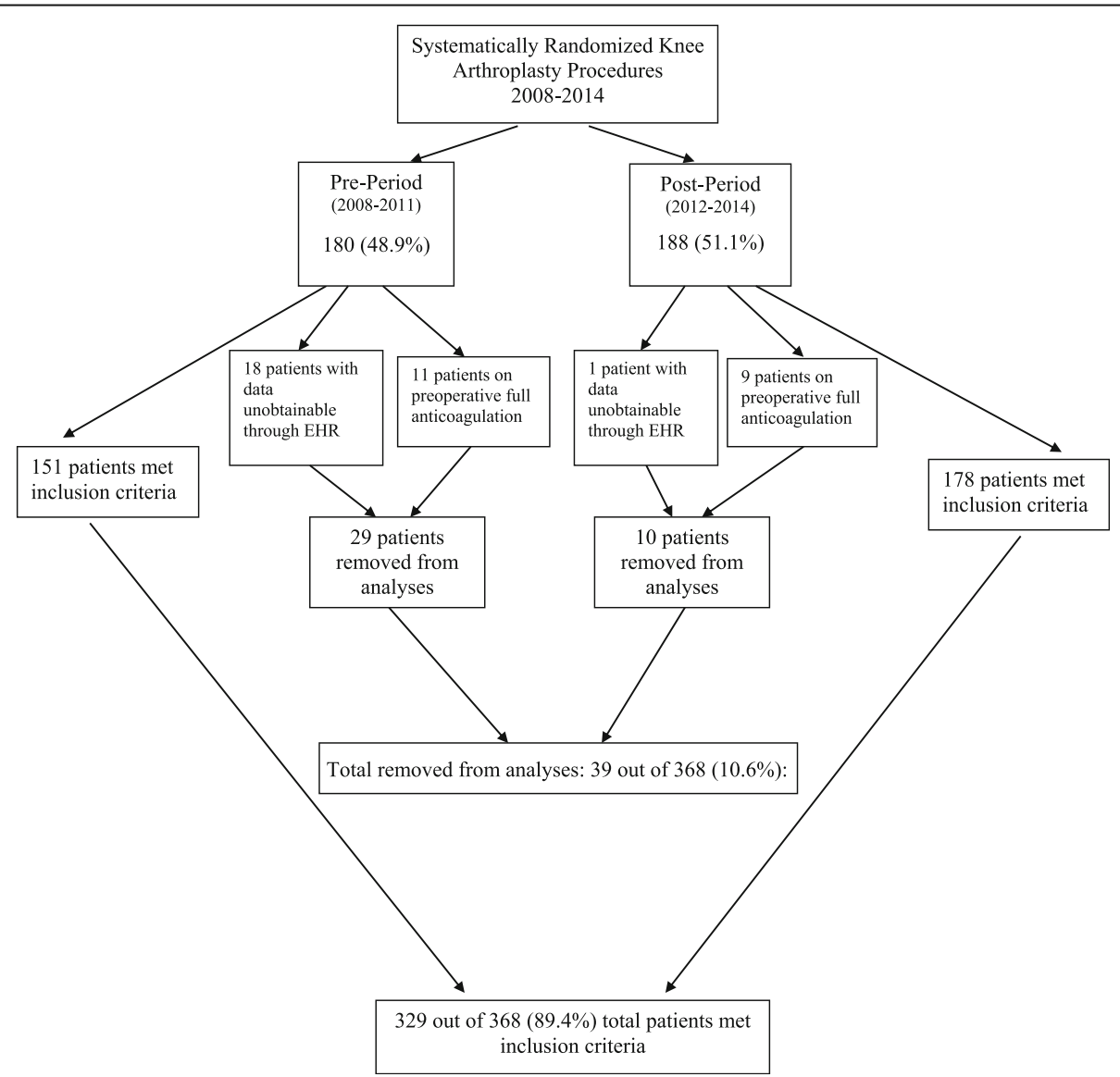

Fig. 1 Study flow chart. A total of 329 patients were included in our study. This represents $89.4 \%$ of patients originally selected via systematic randomization. Patients with a coagulopathy on preoperative anticoagulation or with data unobtainable through the EHR were removed 
Table 1 Patient characteristics

\begin{tabular}{|c|c|c|c|}
\hline Variable & Pre-period & Post-period & $p$ value \\
\hline Male gender $n(\%)$ & $55(36.4)$ & $67(37.6)$ & NS \\
\hline Age, years (standard deviation) & $67.02(10.73)$ & $67.30(10.42)$ & NS \\
\hline BMI categories $\mathrm{kg} / \mathrm{m}^{2}$ & & & NS \\
\hline Underweight <18.5 n (\%) & $0(0)$ & $1(0.56)$ & \\
\hline Normal weight 18.5-24.9 n (\%) & $12(8.11)$ & $13(7.30)$ & \\
\hline Overweight 25-29.9 n (\%) & $36(24.32)$ & $54(30.34)$ & \\
\hline Obese $>30 n(\%)$ & $100(67.57)$ & $110(61.80)$ & \\
\hline Significant comorbidities & & & NS \\
\hline None $n(\%)$ & $141(94.63)$ & $166(93.26)$ & \\
\hline End-stage renal disease $n(\%)$ & $2(1.34)$ & $0(0)$ & \\
\hline Coronary stents $n(\%)$ & $5(3.36)$ & $12(6.74)$ & \\
\hline Cardiac valve replacement (\%) & $1(0.67)$ & $0(0)$ & \\
\hline Current smoker $n(\%)$ & $22(14.97)$ & $27(15.17)$ & NS \\
\hline Malignancy history $n(\%)$ & $21(14.19)$ & $25(14.04)$ & NS \\
\hline Estrogen therapy $n(\%)$ & $1(0.67)$ & $2(1.12)$ & NS \\
\hline History of deep vein thrombosis $n(\%)$ & $3(2.01)$ & $5(2.81)$ & NS \\
\hline Surgery in previous 3 months $n(\%)$ & $2(1.34)$ & $1(0.56)$ & NS \\
\hline Bilateral TKA $n(\%)$ & $5(3.29)$ & $2(1.13)$ & NS \\
\hline
\end{tabular}

difference in the distribution of adjusted risk factors between the pre- and post-periods after excluding those patients that necessitate potent anticoagulation (Table 1). In the pre-period, the most commonly prescribed classes of agents were vitamin $\mathrm{K}$ antagonists (POD1 $35.1 \%$, D/ C $42.1 \%$ ) and Xa inhibitors (POD1 $29.1 \%$, D/C $23.0 \%$ ). In the post-period, ASA monotherapy predominated at both time points (Table 2). There was a statistically significant inverse correlation between VKA and ASA monotherapy prescriptions $(p<0.0001$ and $p<0.0001$ for POD1 and $\mathrm{D} / \mathrm{C}$, respectively) during the study period (Figs. 2 and 3).

\section{Discussion}

Patients undergoing lower extremity orthopedic procedures remain at high risk for developing VTE [1-3]. Orthopedic surgeons are dedicated to reducing this risk, while preventing adverse side effects associated with certain anticoagulant agents [13]. Conflicting CPG and a paucity of high-level evidence have contributed to clinician confusion regarding VTEP decision-making. In 2012, two prominent professional organizations moved toward closer alignment by including ASA monotherapy as an acceptable chemoprophylactic agent $[13,15]$. The results of our study show that there was a statistically

Table 2 Comparing prescribing patterns before and after guideline convergence

\begin{tabular}{|c|c|c|c|c|c|c|}
\hline Class of VTEP agent & $\begin{array}{l}\text { Pre-period POD1 } \\
n(\%)\end{array}$ & $\begin{array}{l}\text { Post-period POD1 } \\
n(\%)\end{array}$ & $p$ value & $\begin{array}{l}\text { Pre-period discharge } \\
n(\%)\end{array}$ & $\begin{array}{l}\text { Post-period discharge } \\
n(\%)\end{array}$ & $p$ value \\
\hline ASA monotherapy $^{a}$ & $7(4.64)$ & $79(44.38)$ & \multirow[t]{7}{*}{$<0.0001$} & $21(13.91)$ & 99 (55.62) & \multirow[t]{7}{*}{$<0.0001$} \\
\hline All other agents & $144(95.36)$ & $99(55.62)$ & & $130(86.09)$ & $79(44.38)$ & \\
\hline $\mathrm{LMWH}^{\mathrm{b}}$ & $32(21.19)$ & $10(5.62)$ & & $26(17.22)$ & $13(7.30)$ & \\
\hline Vitamin $\mathrm{K}$ antagonist & $57(37.75)$ & $31(17.42)$ & & $64(42.38)$ & $35(19.66)$ & \\
\hline Xa inhibitors ${ }^{c}$ & $44(29.14)$ & $36(20.22)$ & & $35(23.18)$ & $20(11.24)$ & \\
\hline Combination $^{d}$ & $11(7.28)$ & $20(11.24)$ & & $5(3.31)$ & $11(6.18)$ & \\
\hline LDUH 5000 U TID & $0(0)$ & $2(1.12)$ & & $0(0)$ & $0(0)$ & \\
\hline
\end{tabular}

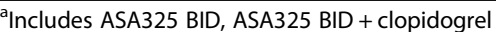

${ }^{b}$ Includes enoxaparin $40 \mathrm{mg} /$ day, enoxaparin $30 \mathrm{mg} /$ day, enoxaparin $30 \mathrm{mg}$ BID

Includes fondaparinux, rivaroxaban, apixaban

IIncludes Xa inhibitor + ASA81, warfarin + Xa inhibitor, warfarin + ASA81, warfarin + clopidogrel, warfarin + ASA325 + clopidogrel, ASA325BID + Xa inhibitor,

warfarin + enoxaparin, ASA325 + enoxaparin 


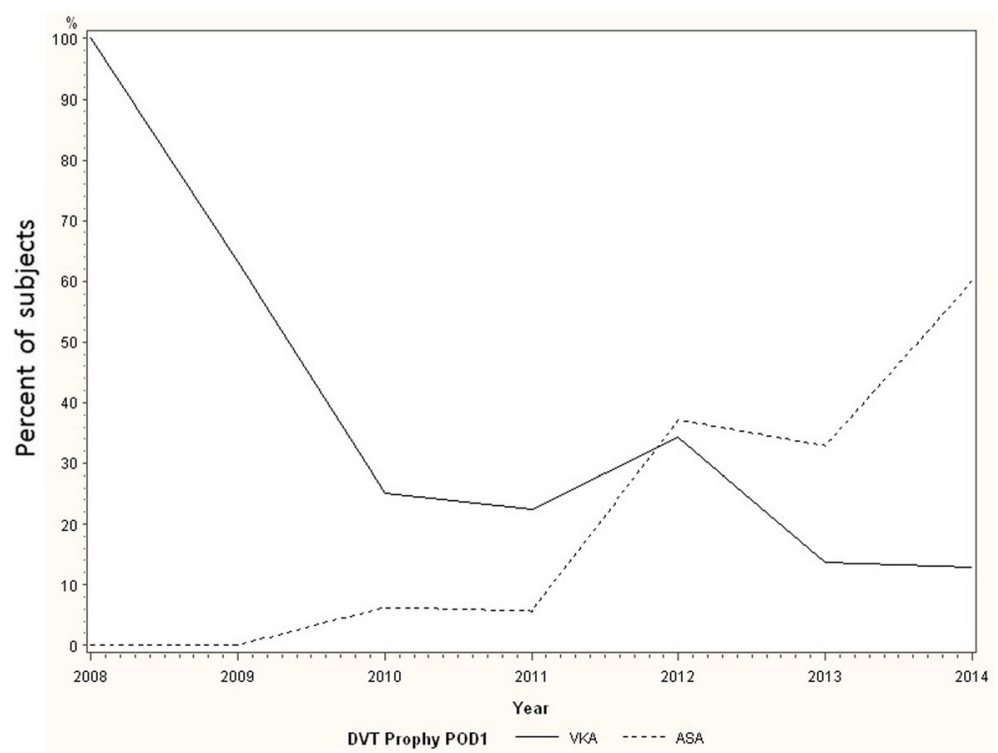

Fig. 2 VTEP prescription rates on postoperative day 1. The percentage of patients prescribed ASA monotherapy on POD\#1 increased significantly after guideline convergence. There was a simultaneous decrease in the percentage of patients prescribed VKA

significant increase in ASA monotherapy prescriptions after the convergence of AAOS and ACCP CPG, thus supporting the notion that CPG can influence physician practices.

The results of our study can help other clinicians overcome what has been described as "inertia of previous practice" [26], provide guidance on VTEP agent selection, and ultimately highlight the profound impact of CPG on clinician prescribing patterns. While some authors suggest that CPG may have a limited impact, other literature on the role of CPG suggests that nationally developed guidelines, especially when endorsed by professional specialty organizations, are a key element to altering physician behavior [16-18, 20, 27-32]. CPG appear to play a large role in VTEP selection, especially when considering that in the absence of an obvious optimal agent, many surgeons state that they rely on guidelines put forth by leading specialty organizations for practice guidance [31]. Furthermore, there is an increased acceptance of national guidelines when colleagues endorse change and incorporate it into practice [33, 34].

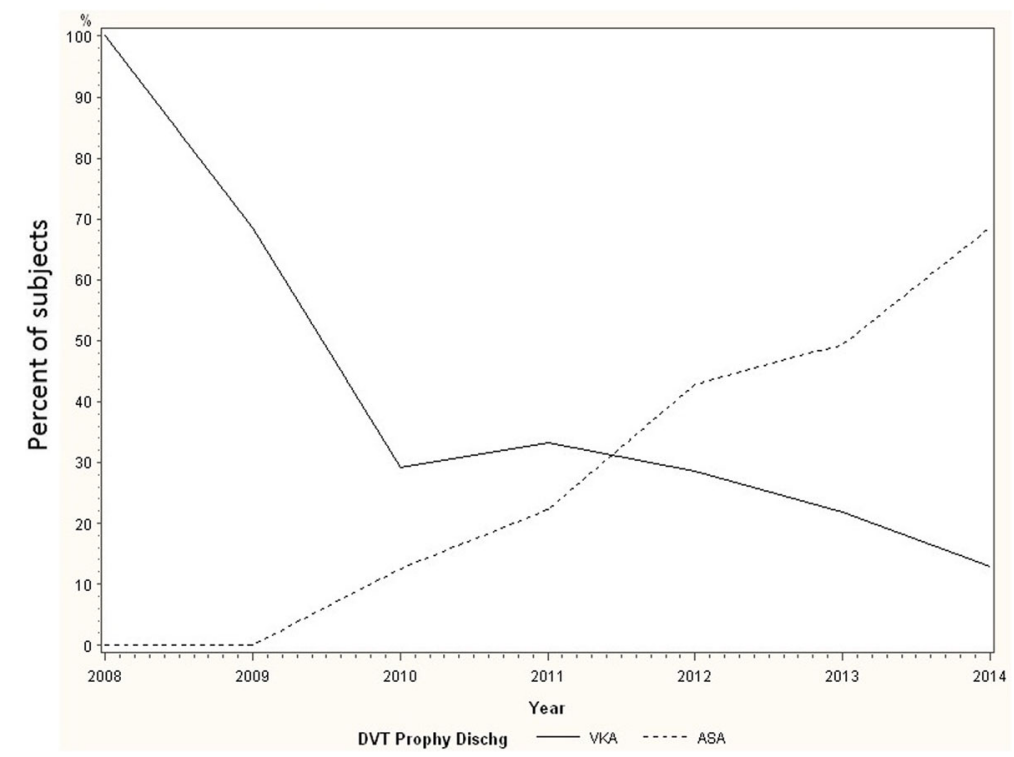

Fig. 3 VTEP prescription rates on discharge. A similar change in VTEP prescribing was observed at discharge. A significant increase in ASA monotherapy prescribing occurred while VKA prescribing decreased 
Prior to 2012, orthopedic surgeons were aware of VTEP CPG and data supporting the use of ASA but hesitated to adopt new practices. A 2008 survey of the members of the American Association of Hip and Knee Surgeons (AAHKS) suggested that roughly $90 \%$ of respondents were familiar with the AAOS or ACCP guidelines. The AAHKS survey provided key perspectives on the then divergent AAOS and ACCP guidelines: $82 \%$ of surgeons agreed more with the AAOS guidelines and $74 \%$ believed the ACCP guidelines were not relevant to orthopedics. Although respondents agreed that enoxaparin was the most efficacious agent, $68 \%$ of surgeons reported that ASA was the easiest to use with the lowest risk profile for bleeding and wound drainage [31].

The AAHKS survey provided key insight regarding VTEP agent selection. The divergence in guidelines steered physicians away from ASA and toward the more potent anticoagulants, such as LMWH or VKA, advocated by the ACCP. The same survey revealed that $53 \%$ of surgeons had adjusted their practice based on guidelines issued by AAOS and ACCP, with a significant portion acknowledging that malpractice claims had directly influenced a change in their practice [31]. Despite data supporting the use of ASA, orthopedic surgeons had resisted changing their prescribing patterns for malpractice defensive concerns [26, 35].

Numerous possible factors may be responsible for our study conclusion. In one recent study, potent anticoagulants such as LMWH, fondaparinux, or VKA were associated with higher all-cause mortality and incidence of clinical non-fatal PE after hip and KA [26]. Additionally, data suggests that ASA is comparable to other agents in preventing VTE and non-fatal PE $[10,36]$. Moreover, the pulmonary embolism prevention trial demonstrated a protective effect of ASA against symptomatic deep vein thrombosis (DVT) and PE of 29 and $43 \%$, respectively, versus placebo [9]. Perhaps paramount of all, ASA may be favored clinically for its lower bleeding risk profile
[10, 37, 38] and its rapid, inexpensive reversal capability [39]. These benefits make ASA favorable for concomitant use in regional anesthesia as opposed to other agents, such as LMWH, where it is a relative contraindication [10]. Finally, ASA is cost-effective, as it does not require hematologic monitoring or insurance approval [8]. The capability of ASA as a VTEP agent in "at risk" populations is documented in both the medical and orthopedic literature $[9,10,36]$. Prior to guideline convergence, orthopedic surgeons were admittedly influenced by the legal ramifications of their prescribing patterns and generally opted for more potent agents with less optimal side effect profiles.

While evidence supporting the increased risk of more potent anticoagulants became available during or after 2014 [40-42], surgeons were already cognizant of the increased risk associated with more potent anticoagulants. This discrepancy may confound our conclusion and help explain the gradual shift toward ASA seen over the entirety of the study period. However, there was a statistically significant increase in ASA monotherapy prescriptions after the convergence of ACCP and AAOS recommendations.

Vitamin $\mathrm{K}$ antagonists and Xa inhibitors were the most widely prescribed VTEP agents in the pre-period, while ASA predominated post-convergence. The observed use of Xa inhibitors is noteworthy due to the timing of their development and approval (Fig. 4). The use of Xa inhibitors for VTEP after KA was supported by the AAOS and ACCP prior to their convergence on ASA $[1,11,12,15]$. The FDA approved fondaparinux in 2001 for VTEP after hip and knee replacement surgery [43]. A randomized clinical trial showed fondaparinux to be more effective in preventing VTE than enoxaparin (30 U BID) in patients undergoing elective major knee surgery, but with an increased risk of major bleeding [44]. The FDA approved rivaroxaban in 2011 for VTEP after hip and knee replacement surgery [45]. The

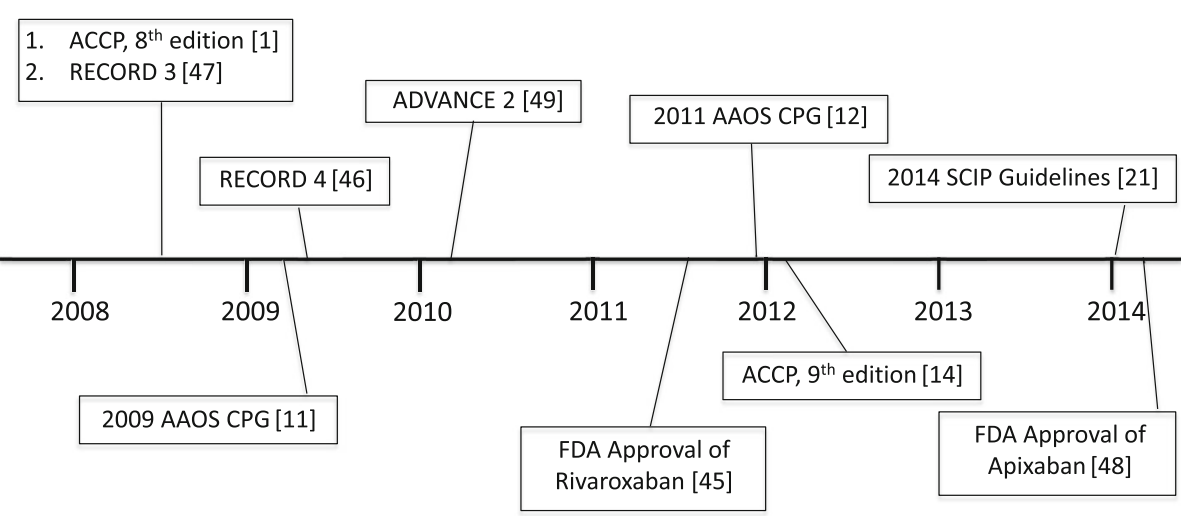

Fig. 4 Timeline of relevant VTEP events. Significant events related to VTEP prescribing after TKA during our study period. Events related to CPG, relevant randomized clinical trials, and FDA approval of medications were included 
RECORD 3 and RECORD 4 randomized trials showed rivaroxaban to be superior to enoxaparin for VTEP after TKA, with similar bleeding rates [46, 47]. The FDA approved apixaban for VTEP after hip and knee surgery in 2014 [48]. The ADVANCE-2 randomized clinical trial showed apixaban to be a convenient and more effective alternative to Lovenox after KA without increased bleeding risk [49]. However, the lack of an available Xa inhibitor reversal agent is a major concern for clinicians [50]. Although the 2008 AAHKS member survey respondents felt that fondaparinux was more effective than ASA, the perceived bleeding risk and lack of reversal agent steered respondents away from $\mathrm{Xa}$ inhibitors [31]. This disadvantage of Xa inhibitors further elucidates the appeal of ASA monotherapy for VTEP after KA.

Various factors impact providers' VTEP agent choice. Assessing VTE risk is multifactorial and often requires an individualized patient-specific approach. There were no differences in preoperative VTE risk between our two study groups (after excluding patients that necessitated full anticoagulation), showing that there is no bias toward more potent anticoagulation in one study population versus the other. In 2014, the ACCP published a weighted risk index utilizing seven VTE risk factors in order to aid providers in risk-stratifying surgical patients. The risk model analyzed the following factors: history of VTE, current neoplasm, sepsis, age greater or equal to 60 years, BMI greater or equal to $40 \mathrm{~kg} / \mathrm{m}^{2}$, male sex, and family history of VTE [3]. We examined five of these factors with other validated factors associated with increased VTE risk (estrogen therapy [24], smoking status, unilateral versus bilateral procedures [25], or surgery within 3 months). Family history of VTE was not available from the EHR and thus not included. None of the patients in our study had a diagnosis of sepsis immediately prior to surgery.

Financial implications influence prescribing patterns as well [51]. As such, one potential confounder to our conclusion is the inclusion of ASA in the new Surgical Care Improvement Project (SCIP) recommendations [21]. Adherence to core measures, such as SCIP, is directly related to reimbursement. In 2014, the Joint Commission amended the recommendation for VTE prophylaxis for SCIP to include aspirin as an acceptable agent. However, the differences in ASA prescribing seen in our study were significant prior to these 2014 changes.

Although prospective randomized trials are needed to compare the efficacy of ASA with other VTEP agents, ASA is now a predominant part of the VTEP armamentarium after KA. Although only two institutions were reviewed, we believe that our results can be representative of medical practice in the USA because of the diversity of our patient population. Limitations include the retrospective design, which may diminish the validity of the study conclusion. Also, retrieval analysis limitations have the potential to introduce selection and/or transfer bias; 19/368 charts (5.2 \%) were unable to be retrieved.

\section{Conclusions}

With no difference seen in the adjusted VTE risk between the two study populations, we conclude that the convergence of AAOS and ACCP CPG influenced orthopedic surgeons to incorporate ASA monotherapy into clinical practice for VTEP after KA procedures.

\section{Abbreviations}

ACCP: American College of Chest Physicians; BID: Twice-daily; CPG: Clinical practice guidelines; D/C: Discharge; EHR: Electronic health record; KA: Knee arthroplasty; LDUH: Low-dose unfractionated heparin; LMWH: Low molecular weight heparin; POD1: Post-operative day 1; VKA: Vitamin K antagonist;

VTE: Venous thromboembolism; VTEP: Venous thromboembolism prophylaxis

\section{Acknowledgements}

The authors are grateful for the assistance on this investigation by the following individuals: David Rosenberg, Martin Lesser, Lusana Ahsan, Mohammad Kazemi, Dev Shah, Alyssa Rothman, Safiya Richardson, and Frank Batliwalla.

Drs. Shah, Satin, and Mullen are resident physicians in the Department of Orthopaedic Surgery at Long Island Jewish Medical Center in the Northwell Health System. Ms. Merwin is the director of Clinical Research in the Department of Orthopaedic Surgery at Montefiore Medical Center. Dr. Goldin is an attending physician in the Department of Medicine at Long Island Jewish Medical Center and an assistant professor of Medicine at Hofstra Northwell School of Medicine. Dr. Sgaglione is a professor and the Chair of Orthopaedic Surgery at the Hofstra Northwell School of Medicine.

\section{Funding}

No funding was obtained for the completion of this project.

\section{Availability of data and materials}

The datasets generated during and/or analyzed during the current study are not available to non-study participants because they contain protected health information.

\section{Authors' contributions}

All authors contributed to the writing and review of the manuscript. SS, AS, and JM contributed to the study design and completed the data collection. All authors read and approved the final manuscript.

\section{Competing interests}

The authors declare that they have no competing interests.

\section{Consent for publication}

Not applicable.

\section{Ethics approval}

The Northwell Health System Institutional Review Board approved this study (IRB\# 14-690)

\section{Author details}

'Department of Orthopaedic Surgery, Long Island Jewish Medical Center, 270-05 76th Ave, New Hyde Park, NY 11040, USA. ${ }^{2}$ Department of Orthopaedic Surgery, Montefiore Medical Center, 111 E 210th St, Bronx, NY 10467, USA. ${ }^{3}$ Department of Medicine, Long Island Jewish Medical Center, 270-05 76th Ave, New Hyde Park, NY 11040, USA.

Received: 23 July 2016 Accepted: 1 October 2016 Published online: 20 October 2016

\section{References}

1. Geerts WH, Bergqvist D, Pineo GF, Heit JA, Samama CM, Lassen MR, Colwell CW, American College of Chest P. Prevention of venous thromboembolism: 
American College of Chest Physicians Evidence-Based Clinical Practice Guidelines (8th edition). Chest. 2008;133:381S-453.

2. Bjornara BT, Gudmundsen TE, Dahl OE. Frequency and timing of clinical venous thromboembolism after major joint surgery. J Bone Joint Surg Br. 2006;88:386-91.

3. Pannucci CJ, Laird S, Dimick JB, Campbell DA, Henke PK. A validated risk model to predict 90-day VTE events in postsurgical patients. Chest. 2014; 145:567-73.

4. Edelsberg J, Ollendorf D, Oster G. Venous thromboembolism following major orthopedic surgery: review of epidemiology and economics. Am J Health Syst Pharm. 2001;58 Suppl 2:S4-13.

5. Losina E, Thornhill TS, Rome BN, Wright J, Katz JN. The dramatic increase in total knee replacement utilization rates in the United States cannot be fully explained by growth in population size and the obesity epidemic. J Bone Joint Surg Am. 2012;94:201-7.

6. Cram P, Lu X, Kates SL, Singh JA, Li Y, Wolf BR. Total knee arthroplasty volume, utilization, and outcomes among Medicare beneficiaries, 1991-2010. JAMA. 2012;308:1227-36.

7. Ruppert A, Steinle T, Lees M. Economic burden of venous thromboembolism: a systematic review. J Med Econ. 2011;14:65-74.

8. Hovens MM, Snoep JD, Tamsma JT, Huisman MV. Aspirin in the prevention and treatment of venous thromboembolism. J Thromb Haemost. 2006;4: $1470-5$.

9. Thomas DP. PEP trial. Pulmonary Embolism Prevention. Lancet. 2000;356: 249-50. author reply 250-241.

10. Lotke PA, Lonner JH. The benefit of aspirin chemoprophylaxis for thromboembolism after total knee arthroplasty. Clin Orthop Relat Res. 2006; 452:175-80.

11. Johanson NA, Lachiewicz PF, Lieberman JR, Lotke PA, Parvizi J, Pellegrini V, Stringer TA, Tornetta 3rd P, Haralson 3rd RH, Watters 3rd WC. Prevention of symptomatic pulmonary embolism in patients undergoing total hip or knee arthroplasty. J Am Acad Orthop Surg. 2009;17:183-96.

12. Mont MA, Jacobs JJ, Boggio LN, Bozic KJ, Della Valle CJ, Goodman SB, Lewis CG, Yates AJ, Watters WC, Turkelson CM, et al. Preventing venous thromboembolic disease in patients undergoing elective hip and knee arthroplasty. J Am Acad Orthop Surg. 2011;19:768-76.

13. Preventing venous thromboembolic disease in patients undergoing elective hip and knee arthroplasty. Evidence based guidelines and evidence report. [http://www.aaos.org/research/guidelines/NTENTE_full_guideline.pdf].

14. Guyatt GH, Norris SL, Schulman S, Hirsh J, Eckman MH, Akl EA, Crowther M, Vandvik PO, Eikelboom JW, McDonagh MS, et al. Methodology for the development of antithrombotic therapy and prevention of thrombosis guidelines: antithrombotic therapy and prevention of thrombosis, 9th ed: American College of Chest Physicians Evidence-Based Clinical Practice Guidelines. Chest. 2012;141:53S-70.

15. Falck-Ytter Y, Francis CW, Johanson NA, Curley C, Dahl OE, Schulman S, Ortel TL, Pauker SG, Colwell Jr CW, American College of Chest P. Prevention of VTE in orthopedic surgery patients: antithrombotic therapy and prevention of thrombosis, 9th ed: American College of Chest Physicians Evidence-Based Clinical Practice Guidelines. Chest. 2012;141:e278S-325.

16. Greco PJ, Eisenberg JM. Changing physicians' practices. N Engl J Med. 1993; 329:1271-3.

17. Doyne EO, Alfaro MP, Siegel RM, Atherton HD, Schoettker PJ, Bernier J, Kotagal UR. A randomized controlled trial to change antibiotic prescribing patterns in a community. Arch Pediatr Adolesc Med. 2004;158:577-83.

18. Audet AM, Greenfield S, Field M. Medical practice guidelines: current activities and future directions. Ann Intern Med. 1990;113:709-14.

19. Duval M, Desrosiers M. Guidelines for management of acute bacterial rhinosinusitis: impact on Quebec physicians' prescriptions for antibiotics. Otolaryngol Head Neck Surg. 2007;136:258-60.

20. Sbarbaro JA. Can we influence prescribing patterns? Clin Infect Dis. 2001;33 Suppl 3:S240-4.

21. VTE Fact Sheet. [http://www.jointcommission.org/assets/1/6NTE_Fact_ sheet_Jan_2014.pdf].

22. Grimshaw JM, Russell IT. Effect of clinical guidelines on medical practice: a systematic review of rigorous evaluations. Lancet. 1993;342:1317-22.

23. Lugtenberg M, Burgers JS, Westert GP. Effects of evidence-based clinical practice guidelines on quality of care: a systematic review. Qual Saf Health Care. 2009;18:385-92.

24. London: Royal College of Physicians (UK). Venous thromboembolism: reducing the risk of venous thromboembolism (deep vein thrombosis and pulmonary embolism) in patients admitted to hospital. London: National Institute for Health and Clinical Excellence: Guidance; 2010

25. Della Valle CJ, Steiger DJ, Di Cesare PE. Thromboembolism after hip and knee arthroplasty: diagnosis and treatment. J Am Acad Orthop Surg. 1998;6: $327-36$

26. Sharrock NE, Gonzalez Della Valle A, Go G, Lyman S, Salvati EA. Potent anticoagulants are associated with a higher all-cause mortality rate after hip and knee arthroplasty. Clin Orthop Relat Res. 2008:466:714-21.

27. Davis DA, Taylor-Vaisey A. Translating guidelines into practice. A systematic review of theoretic concepts, practical experience and research evidence in the adoption of clinical practice guidelines. CMAJ. 1997;157:408-16.

28. Kosecoff J, Kanouse DE, Rogers WH, McCloskey L, Winslow CM, Brook RH. Effects of the National Institutes of Health Consensus Development Program on physician practice. JAMA. 1987;258:2708-13.

29. Lomas J, Anderson GM, Domnick-Pierre K, Vayda E, Enkin MW, Hannah WJ. Do practice guidelines guide practice? The effect of a consensus statement on the practice of physicians. N Engl J Med. 1989:321:1306-11.

30. Grol R. Implementing guidelines in general practice care. Qual Health Care. 1992;:1:184-91.

31. Markel DC, York S, Liston Jr MJ, Flynn JC, Barnes CL, Davis 3rd CM, Committee AR. Venous thromboembolism: management by American Association of Hip and Knee Surgeons. J Arthroplasty. 2010;25:3-9.e1-2.

32. Cabana MD, Rand CS, Powe NR, Wu AW, Wilson MH, Abboud PA, Rubin HR. Why don't physicians follow clinical practice guidelines? A framework for improvement. JAMA. 1999;282:1458-65.

33. Mont M, Jacobs J, Lieberman J, Parvizi J, Lachiewicz P, Johanson N, Watters W, Prophylaxis AGDWGPV, Prophylaxis AGDWGPV. Preventing venous thromboembolic disease in patients undergoing elective total hip and knee arthroplasty. J Bone Joint Surg Am. 2012;94A:673-4.

34. Lomas J, Haynes RB. A taxonomy and critical review of tested strategies for the application of clinical practice recommendations: from "official" to "individual" clinical policy. Am J Prev Med. 1988:4:77-94. discussion 95-77.

35. Kessler DP, Summerton N, Graham JR. Effects of the medical liability system in Australia, the UK, and the USA. Lancet. 2006:368:240-6.

36. Bozic KJ, Vail TP, Pekow PS, Maselli JH, Lindenauer PK, Auerbach AD. Does aspirin have a role in venous thromboembolism prophylaxis in total knee arthroplasty patients? J Arthroplasty. 2010;25:1053-60.

37. Dorr LD, Gendelman V, Maheshwari AV, Boutary M, Wan Z, Long WT. Multimodal thromboprophylaxis for total hip and knee arthroplasty based on risk assessment. J Bone Joint Surg Am. 2007;89:2648-57.

38. Lee MC, Nickisch F, Limbird RS. Massive retroperitoneal hematoma during enoxaparin treatment of pulmonary embolism after primary total hip arthroplasty: case reports and review of the literature. J Arthroplasty. 2006; 21:1209-14.

39. Powner DJ, Hartwell EA, Hoots WK. Counteracting the effects of anticoagulants and antiplatelet agents during neurosurgical emergencies. Neurosurgery. 2005;57:823-31. discussion 823-831.

40. Mostafavi Tabatabaee R, Rasouli MR, Maltenfort MG, Parvizi J. Cost-effective prophylaxis against venous thromboembolism after total joint arthroplasty: warfarin versus aspirin. J Arthroplasty. 2015;30:159-64.

41. Huang R, Buckley PS, Scott B, Parvizi J, Purtill JJ. Administration of aspirin as a prophylaxis agent against venous thromboembolism results in lower incidence of periprosthetic joint infection. J Arthroplasty. 2015;30:39-41.

42. Raphael IJ, Tischler EH, Huang R, Rothman RH, Hozack WJ, Parvizi J. Aspirin: an alternative for pulmonary embolism prophylaxis after arthroplasty? Clin Orthop Relat Res. 2014;472:482-8.

43. NDA Approval. [http://www.accessdata.fda.gov/drugsatfda_docs/nda2001/ 21-345_Arixtra_Approv.pdf].

44. Bauer KA, Eriksson BI, Lassen MR, Turpie AG, Steering Committee of the Pentasaccharide in Major Knee Surgery S. Fondaparinux compared with enoxaparin for the prevention of venous thromboembolism after elective major knee surgery. N Engl J Med. 2001;345:1305-10.

45. NDA Approval. [http://www.accessdata.fda.gov/drugsatfda_docs/appletter/ 2011/022406s000ltr.pdf].

46. Turpie AG, Lassen MR, Davidson BL, Bauer KA, Gent M, Kwong LM, Cushner FD, Lotke PA, Berkowitz SD, Bandel TJ, et al. Rivaroxaban versus enoxaparin for thromboprophylaxis after total knee arthroplasty (RECORD4): a randomised trial. Lancet. 2009;373:1673-80.

47. Lassen MR, Ageno W, Borris LC, Lieberman JR, Rosencher N, Bandel TJ, Misselwitz F, Turpie AG, Investigators R. Rivaroxaban versus enoxaparin for thromboprophylaxis after total knee arthroplasty. N Engl J Med. 2008;358:2776-86. 
48. Supplement Approval. [http://www.accessdata.fda.gov/drugsatfda_docs/ appletter/2014/2021550rig1s003ltr.pdf].

49. Lassen MR, Raskob GE, Gallus A, Pineo G, Chen D, Hornick P, investigators A-. Apixaban versus enoxaparin for thromboprophylaxis after knee replacement (ADVANCE-2): a randomised double-blind trial. Lancet. 2010; 375:807-15.

50. Enriquez A, Lip GY, Baranchuk A. Anticoagulation reversal in the era of the non-vitamin K oral anticoagulants. Europace. 2015;18(7):955-64.

51. Lomas J. Teaching old (and not so old) docs new tricks: effective ways to implement research findings. In: Dunn E, Norton P, Stewart M, Tudiver F, Bass M, editors. Disseminating research, changing practice. Thousand Oaks: Sage; 1994. p. 1-18.

Submit your next manuscript to BioMed Central and we will help you at every step:

- We accept pre-submission inquiries

- Our selector tool helps you to find the most relevant journal

- We provide round the clock customer support

- Convenient online submission

- Thorough peer review

- Inclusion in PubMed and all major indexing services

- Maximum visibility for your research

Submit your manuscript at www.biomedcentral.com/submit
Biomed Central 